\title{
Article \\ Elevated Nitrogen Priming Induced Oxinitro-Responses and Water Deficit Tolerance in Rice
}

\author{
Kamolchanok Umnajkitikorn ${ }^{1, *(\mathbb{D})}$, Mitsutaka Fukudome ${ }^{2,3} \mathbb{D}$, Toshiki Uchiumi ${ }^{2} \mathbb{D}$ and Neung Teaumroong ${ }^{4}(\mathbb{D}$ \\ 1 School of Crop Production Technology, Institute of Agricultural Technology, Suranaree University of \\ Technology, Nakhon Ratchasima 30000, Thailand \\ 2 Graduate School of Science and Engineering, Kagoshima University, 1-21-35 Korimoto, \\ Kagoshima 890-0065, Japan; fukudome@nibb.ac.jp (M.F.); uttan@sci.kagoshima-u.ac.jp (T.U.) \\ 3 Division of Symbiotic Systems, National Institute for Basic Biology, Myodaiji, Okazaki, Aichi 444-8585, Japan \\ 4 School of Biotechnology, Institute of Agricultural Technology, Suranaree University of Technology, \\ Nakhon Ratchasima 30000, Thailand; neung@sut.ac.th \\ * Correspondence: k.umnajkitikorn@sut.ac.th; Tel.: +66-44223706
}

Citation: Umnajkitikorn, K.; Fukudome, M.; Uchiumi, T.; Teaumroong, N. Elevated Nitrogen Priming Induced Oxinitro-Responses and Water Deficit Tolerance in Rice. Plants 2021, 10, 381. https:// doi.org/10.3390/plants10020381

Academic Editor: M. Iftikhar Hussain Received: 27 January 2021

Accepted: 11 February 2021

Published: 17 February 2021

Publisher's Note: MDPI stays neutral with regard to jurisdictional claims in published maps and institutional affiliations.

Copyright: (c) 2021 by the authors. Licensee MDPI, Basel, Switzerland. This article is an open access article distributed under the terms and conditions of the Creative Commons Attribution (CC BY) license (https:// creativecommons.org/licenses/by/ $4.0 /)$.

\begin{abstract}
Under water deficit conditions, the essential macronutrient nitrogen becomes limited as a result of reduced dissolved nitrogen and root nitrogen uptake. An elevated nitrogen level might be able to mitigate these effects, integrated with the idea of using nitric oxide as abiotic stress tolerant inducers. In this study, we evaluated the potential of using elevated nitrogen priming prior to water shortage to mitigate plant stress through nitric oxide accumulation. We grew rice plants in $300 \mathrm{mg} \mathrm{L}^{-1}$ nitrogen for 10 weeks, then we primed plants with four different nitrogen concentrations: 100, 300 (control), 500 and $1000 \mathrm{mg} \mathrm{L}^{-1}$ nitrogen prior to inducing water deficit conditions. Plants primed with $500 \mathrm{mg} \mathrm{L}^{-1}$ nitrogen possessed a higher photosynthetic rate, relative water content, electrolyte leakage and lipid peroxidation under water deficit conditions, compared to control plants. The induction of water deficit tolerance was supported with the activation of antioxidant defense system, induced by the accumulation of nitric oxide in leaves and roots of rice plants. We originally demonstrated the accumulation of nitric oxide in leaves of rice plants. The elevated nitrogen priming can be used to enhance water deficit tolerance in irrigated paddy fields, instead of nitric oxide donors.
\end{abstract}

Keywords: rice; nitrogen; water stress; drought; antioxidant; reactive oxygen species; reactive nitrogen species

\section{Introduction}

Water deficit conditions cause widespread crop loss globally due to abiotic stress. By the end of the 21st century, drought and water deficit stress may account for more than 70 percent of crop loss below optimal productivity [1]. There are many methods to cope with stresses from water deficit conditions: breeding strategies, cultural practices, and irrigation approaches [2,3]. Drought stress induces mature and young leaf senescence. The primary site of damage during stress is the chloroplasts, where more than $70 \%$ of the leaf nitrogen $(\mathrm{N})$ is sequestrated. In many annual crop species, chloroplast degradation requires a main strategy to cope with drought stress-known as an escape strategy [4]. This strategy aims to utilize the accumulated nutrients, particularly nitrogen and energy for acclimation and survival during stress episodes [5].

Under water deficit conditions, the loss of transpiration and cell turgor pressure lead to a reduction in uptake and transport of nitrogen, silicon, magnesium and calcium and other important nutrients [6]. Water deficit does not only limit nitrogen uptake but also restricts nitrogen assimilation through the inhibition of enzymes involved in nitrogen metabolism, such as nitrate reductase and glutamine synthetase [7]. Leaf yellowing commonly appears as the consequence of water deficit due to low chlorophyll biosynthesis and high chloroplast and chlorophyll degradation [5]. 
Nitric oxide (NO) has been proposed as a regulator of the antioxidant defense system during stress conditions [8-11]. Cai et al. 2015 found that the activity of nitric oxide synthase (NOS) and the accumulation of NO in rice plants were activated under salinity and drought stress [9]. Transgenic rice plants with overexpression of rat neuronal NO synthase (nNOS) showed an improvement in drought and salt tolerance [9]. External application of nitric oxide (NO) donor S-nitroso-N-acetylpenicillamine (SNAP) also alleviated the damage from salinity stress on chickpea (Cicer arietinum L.) plants [11]. The application of sodium nitroprussiate (SNP) (NO donor) also improved the chilling tolerance of winter wheat via the accumulation of fructan [12]. Spraying rice seedlings with SNP also enhanced drought tolerance, maintained leaf water potential, enhanced the antioxidant defense system and improved the stability of membranes [13]. However, NO donors or the transgenic approach are costly and inapplicable in many parts of the world. We were eager to search for a simplified method to utilize NO-triggered tolerant mechanisms. NO can be generated as a byproduct from a reaction catalyzed with nitrate reductase (NR) [14,15]. NR-generated $\mathrm{NO}$ had a pivotal role in lateral root formation and nitrogen uptake under partial nitrate nutrition in rice [16]. A high level of nitrogen application therefore becomes an interesting option due to the fact that farmers can access and afford nitrogen fertilizer.

Long-term application of high amounts of chemical $\mathrm{N}$ fertilizer lessened the water and nutrient use efficiency as well as inducing environmental problems and sensitivity to insects and diseases $[17,18]$. However, with moderate drought stress an appropriate level of $\mathrm{N}$ application can benefit the growth and yield of rice plants. Applying nitrogen can induce leaf production and thus accelerate transpiration and drought stress severity, and elevated nitrogen application levels may further stimulate rice shoot/root growth, promote photosynthesis, transpiration and yield $[19,20]$. High nitrogen levels also enhanced plasticity of roots, allowing plants to extract more of the water available from the soil [21]. Moreover, high $\mathrm{N}$ application induced a reduction in mesophyll conductance $\left(\mathrm{g}_{\mathrm{m}}\right)$, which limits photosynthetic capacity and N-use efficiency [17]. Some recent studies have also shown that a high level of $\mathrm{N}$ in growing media enhanced the antioxidant defense system and some nitrogen assimilation enzymes, such as glutamine synthetase (GS) and glutamate synthase (GOGAT) but decreased N-use efficiency [22]. Although the effect of a large amount of $\mathrm{N}$ in growing media or in soil has long been seen to promote photosynthesis and $\mathrm{N}$ assimilation in various crop plants, regulation of high $\mathrm{N}$ levels triggering drought tolerance through $\mathrm{NO}$ signaling has never been investigated.

We therefore hypothesized that if we increased the nitrogen concentration in the fertilizer for only a short-period of time (priming), NO accumulation would be activated. Thus, the antioxidant defense system would also be activated. An addition of nitrogen could delay protein and chlorophyll degradation during a short period of water scarcity. In this study we aim to identify the appropriate level of $\mathrm{N}$ for priming treatment prior to stress episodes and to assess the mechanisms of nitrogen induced water deficit tolerance.

\section{Results}

\subsection{Elevated Nitrogen Priming Enhanced Photosynthesis and Leaf Growth under Water Deficit Conditions}

An elevated nitrogen level is well-known for promoting plant growth. However, the effects of an elevated nitrogen level for short term application (priming) on photosynthesis and growth have not been investigated. Rice plants primed with an elevated $\mathrm{N}$ level (500 $\mathrm{mg} \mathrm{L}^{-1}$ and $1000 \mathrm{mg} \mathrm{L}^{-1} \mathrm{~N}$ ) maintained higher photosynthetic activity (Figure 1a), but only the $500 \mathrm{mg} \mathrm{L}^{-1} \mathrm{~N}$ promoted rice plant growth as indicated by increasing leaf area under water deficit conditions (Figure 1b,c) when compared to the control plants (at $300 \mathrm{mg} \mathrm{L}^{-1} \mathrm{~N}$ ). Elevated nitrogen priming failed to alter the net photosynthetic rate or leaf area of rice plants under well-watered conditions. Low $\mathrm{N}$ level priming had lower photosynthetic activity and growth under well-watered conditions (Figure 1). 

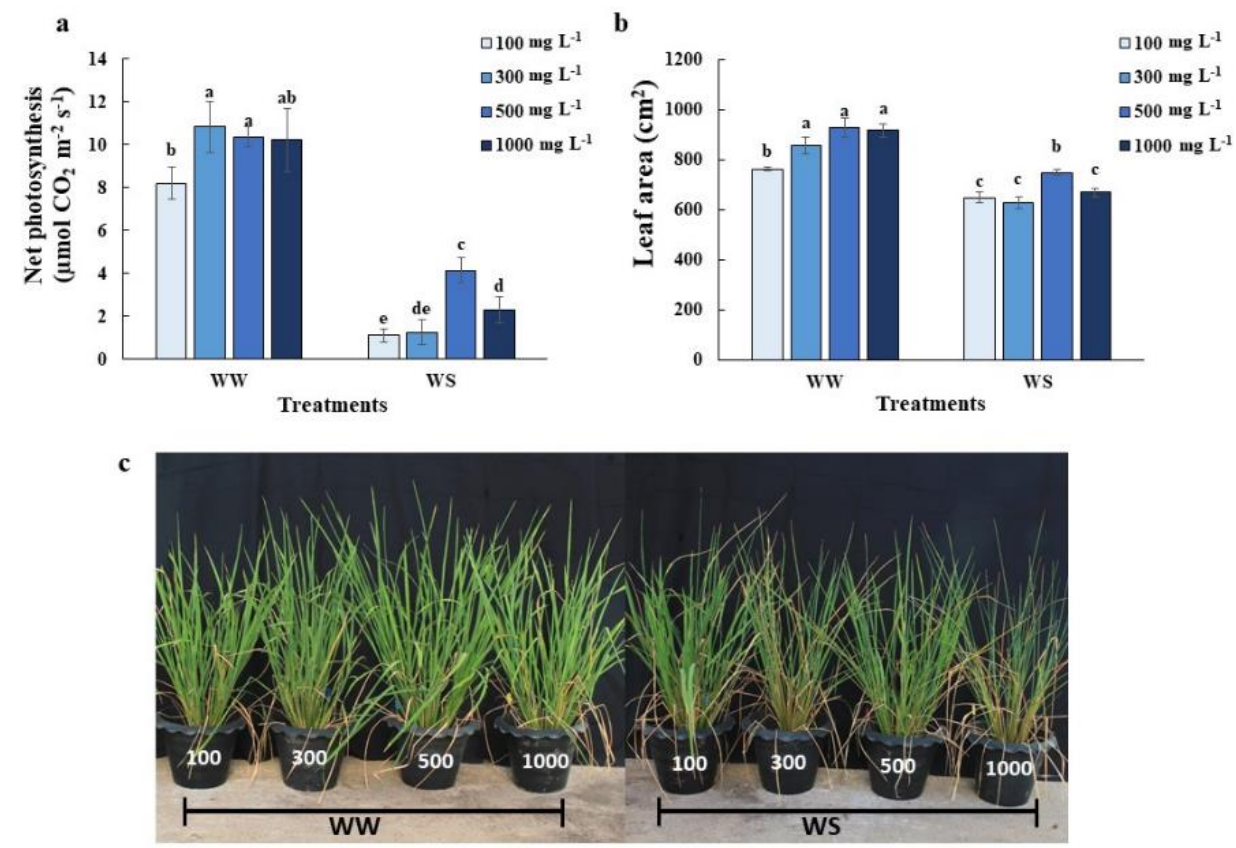

Figure 1. Growth and photosynthesis responses of rice plants to different nitrogen concentration priming. (a) Net photosynthesis of the youngest fully expanded leaves of the greenhouse-grown 11-week old rice plants after maintaining relative soil moisture content at $10-15 \%$ for 7 days (WS), compared with those under well-watered conditions (WW). (b) Leaf area of plants subjected to different level of nitrogen priming. (c) Plant growth under different level of nitrogen priming. The values shown are the Mean \pm SE ( $n=6$ and 10, respectively). The different letters above the bars indicate significant differences by one-way ANOVA and Duncan's test $(p \leq 0.05)$.

\subsection{Elevated Nitrogen Priming Promoted Relatively Higher Leaf Relative Water Content (RWC) under Water Deficit Conditions}

Elevated N-primed rice had higher RWC under water deficit conditions than normal $\mathrm{N}$ and lower $\mathrm{N}$-primed rice (Figure 2a). Stomata conductance and transpiration rate from different priming nitrogen concentrations under water deficit conditions showed no significant differences. However, under well-watered conditions N-primed plants showed significantly lower stomata conductance (Figure 2b,c). A dramatically increased instantaneous water use efficiency occurred only in rice plants subjected to $500 \mathrm{mg} \mathrm{L}^{-1}$ N-priming treatment (Figure 2d).

\subsection{Elevated Nitrogen Priming Alleviated Chlorophyll and Protein Degradation as Well as Cell Damage under Water Deficit Conditions}

The elevated N-primed leaf maintained significantly higher chlorophyll and protein content under water deficit conditions (Figure 3a,b) but had only significantly higher protein content under well-watered conditions (Figure 3b). Electrolyte leakage (EL) was lower in the $500 \mathrm{mg} \mathrm{L}^{-1} \mathrm{~N}$-primed plants and low N-primed plants (Figure 3c). However, excessive $\mathrm{N}$ (1000 $\mathrm{mg} \mathrm{L}^{-1} \mathrm{~N}$ ) had significantly higher electrolyte leakage (Figure 3c).

\subsection{Elevated Nitrogen Priming Enhanced Antioxidant Defense Mechanisms under Water Deficit Conditions}

To elucidate the mechanisms of elevated-N priming in delaying leaf senescence, we investigated the antioxidant defense system. Under well-watered conditions, SOD and CAT activity were the same between different $\mathrm{N}$ priming treatments (Figure $4 \mathrm{a}, \mathrm{b}$ ), while APX activity was slightly lower $100 \mathrm{mg} \mathrm{L}^{-1}$ and $500 \mathrm{mg} \mathrm{L}^{-1} \mathrm{~N}$-primed plants and significantly lower in $1000 \mathrm{mg} \mathrm{L}^{-1} \mathrm{~N}$-primed plants, compared to nonprimed $\left(300 \mathrm{mg} \mathrm{L}^{-1} \mathrm{~N}\right)$ plants (Figure 4c). In contrast, under water deficit conditions, SOD and APX activities significantly 
increased in plants primed with $500 \mathrm{mg} \mathrm{L}^{-1} \mathrm{~N}$, compared to control (Figure 4a,b). However, CAT activity in elevated N-primed plants significantly increased under water deficit conditions, compared to control $\left(300 \mathrm{mg} \mathrm{L}^{-1} \mathrm{~N}\right)$ under well-watered conditions (Figure $4 \mathrm{~b}$ ).
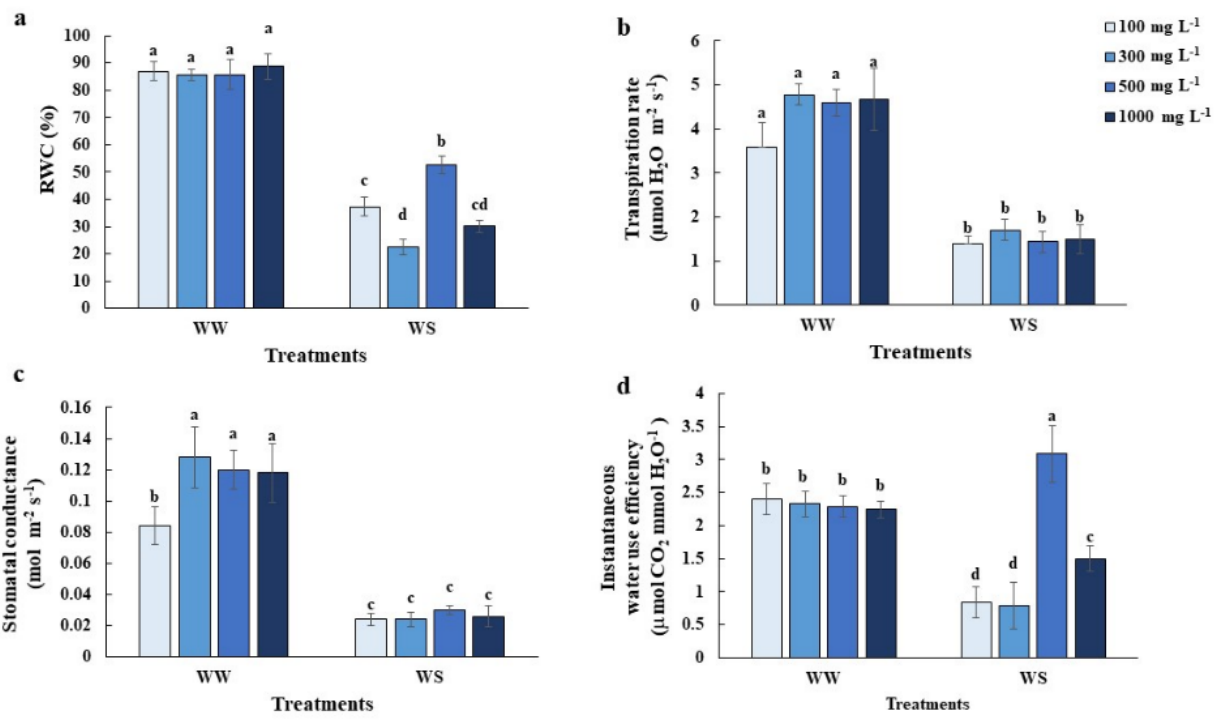

Figure 2. Physiological responses associated with plant water status. (a) relative leaf water content (RWC), (b) stomatal conductance, (c) transpiration rate and (d) instantaneous water use efficiency of the youngest fully expanded leaves of the greenhouse-grown 11-week old rice plants after maintaining relative soil moisture content at 10-15\% for 7 days, compared with those under well-watered conditions $(\mathrm{WW})$. Values are the Mean $\pm \mathrm{SE}(\mathrm{n}=6)$. The different letters above the bars indicate significant differences by one-way ANOVA and Duncan's test $(p \leq 0.05)$.
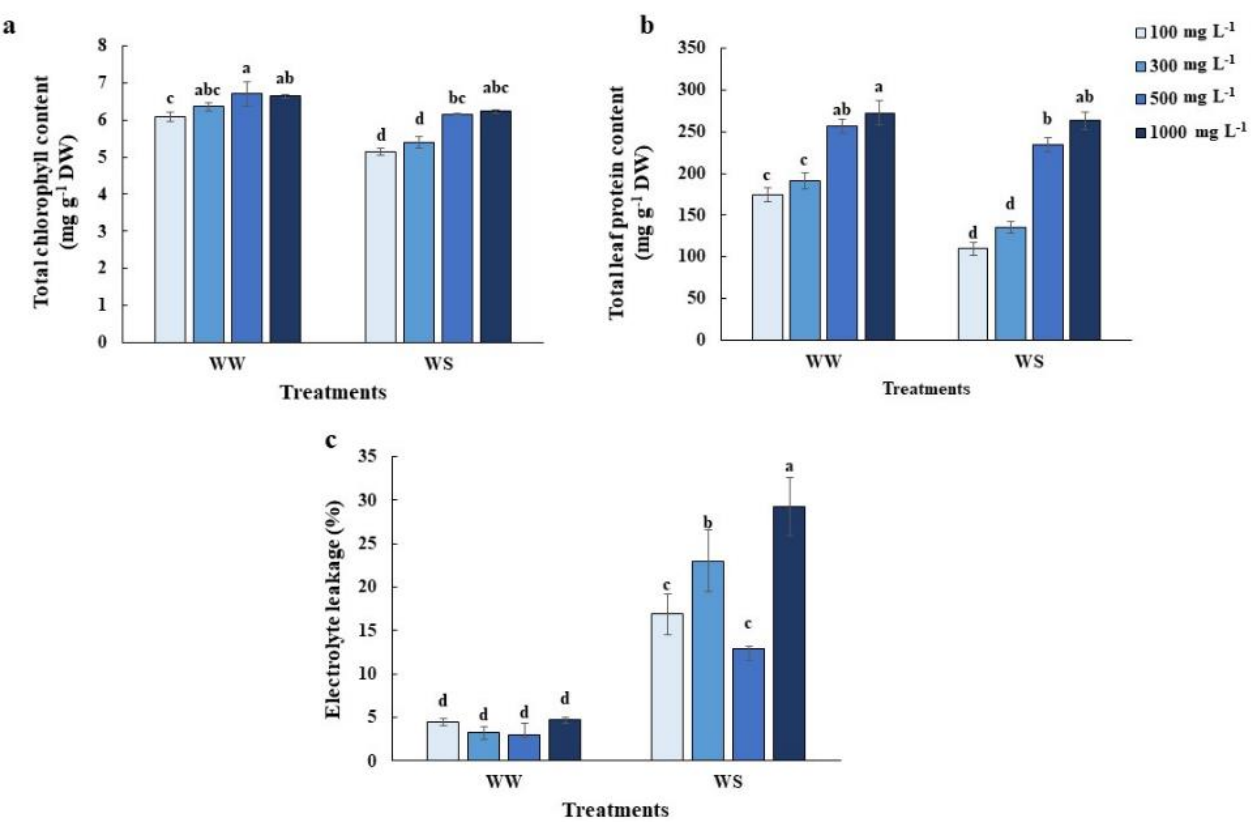

Figure 3. Biochemical responses associated with leaf senescence: (a) Total chlorophyll content, (b) total leaf protein content and (c) electrolyte leakage of the youngest fully expanded leaves of the greenhouse-grown 11-week old rice plants after maintaining relative soil moisture content at 10-15\% for 7 days (WS), compared with those under well-watered conditions (WW). Values shown are the Mean \pm SE ( $n=4,6$ and 4, respectively). The different letters above the bars indicate significant differences by one-way ANOVA and Duncan's test $(p \leq 0.05)$. 

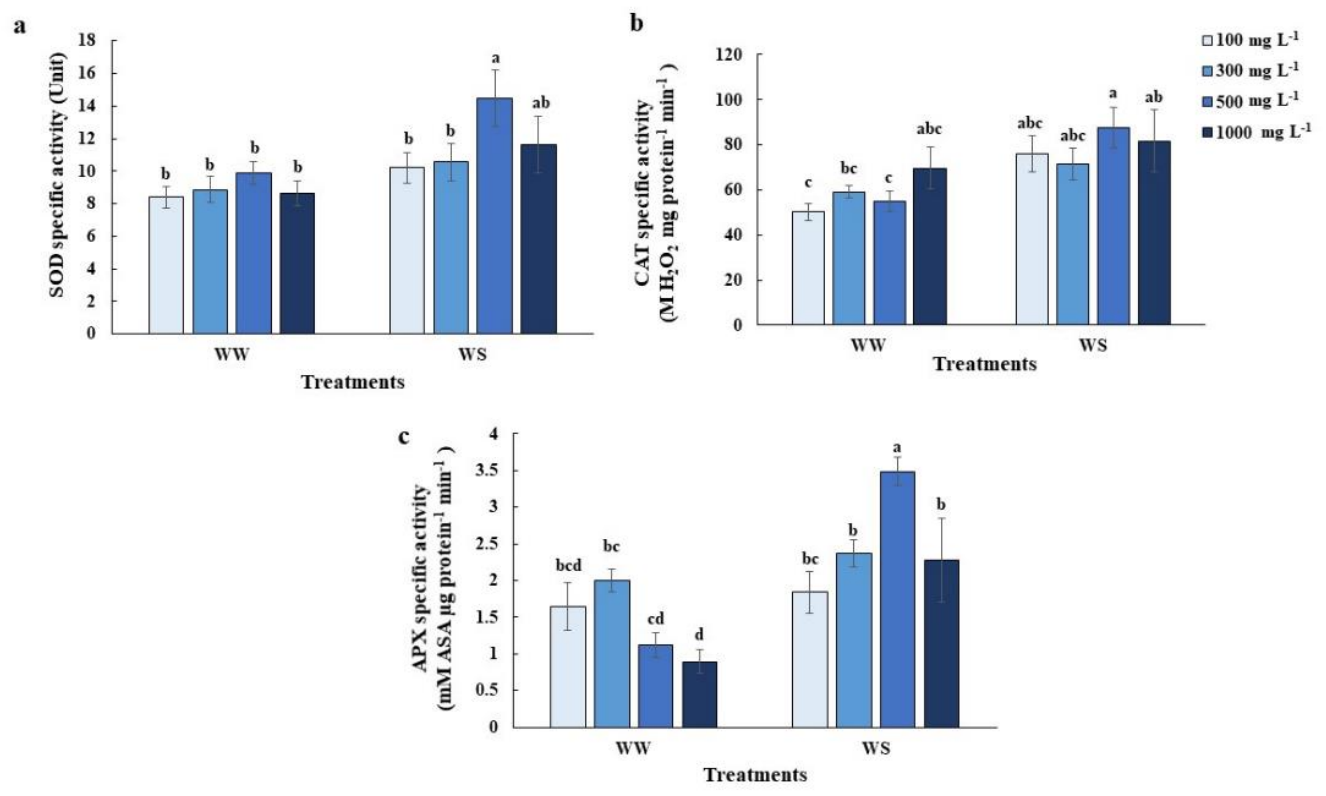

Figure 4. Enzymatic reactive oxygen species (ROS)-scavenging antioxidant responses: (a) Superoxide dismutase (SOD), (b) catalase (CAT) and (c) ascorbate peroxidase (APX) specific activities of the youngest fully expanded leaves of the 5 greenhouse-grown 11-week old rice plants after maintaining relative soil moisture content at $10-15 \%$ for 7 days (WS), compared with those under well-watered conditions $(W W)$. Values are the Mean \pm SE $(n=4)$. The different letters above the bars indicate significant differences by one-way ANOVA and Duncan's test $(p \leq 0.05)$.

2.5. Nitric Oxide Accumulation in Elevated Nitrogen Primed-Plants Alleviated Reactive Oxygen Species (ROS) Accumulation under Water Deficit Conditions

To further investigate the mechanisms underlining the elevated nitrogen priming in alleviation of oxidative damage, we therefore focused on the nitric oxide signaling which has been reported to trigger antioxidant defense mechanisms and set up an in-lab experiment to investigate the process with the application of nitric oxide donor and scavenger. Nitric oxide (NO) accumulation occurred under the PEG-induced water deficit conditions for elevated nitrogen primed plant roots and leaves (500D), and plants without elevated nitrogen priming but supplied with a nitric oxide donor, sodium nitroprusside (SNP) (300D + SNP) (Figure 5). In contrast, the released NO and histological NO accumulation remained low under PEG-induced water deficit in the plant without elevated $\mathrm{N}$ priming (300D) and plants-primed with $500 \mathrm{mg} \mathrm{L}^{-1} \mathrm{~N}$ but supplied with a NO scavenger, 2-(4-carboxyphenyl)-4,4,5,5-tetramethylimidazoline-1-oxyl-3-oxide (cPTIO) (500D + cPTIO) (Figure 5).

Additionally, $\mathrm{H}_{2} \mathrm{O}_{2}$ content and staining showed low ROS levels in roots and leaves in plants without PEG treatment (control condition) (Figures 6 and 7a,b). The accumulation of ROS and lipid peroxidation were induced by PEG as shown in 300D. However, ROS and MDA content remained low in 500D plants and 300D +SNP (Figures 6 and 7), while the endogenous $\mathrm{NO}$ and released $\mathrm{NO}$ were more pronounced in these treatments (Figures 6 and 7). The CPTIO also inverted elevated nitrogen priming effects, leading to ROS accumulation and lipid peroxidation (Figures 6 and 7). 

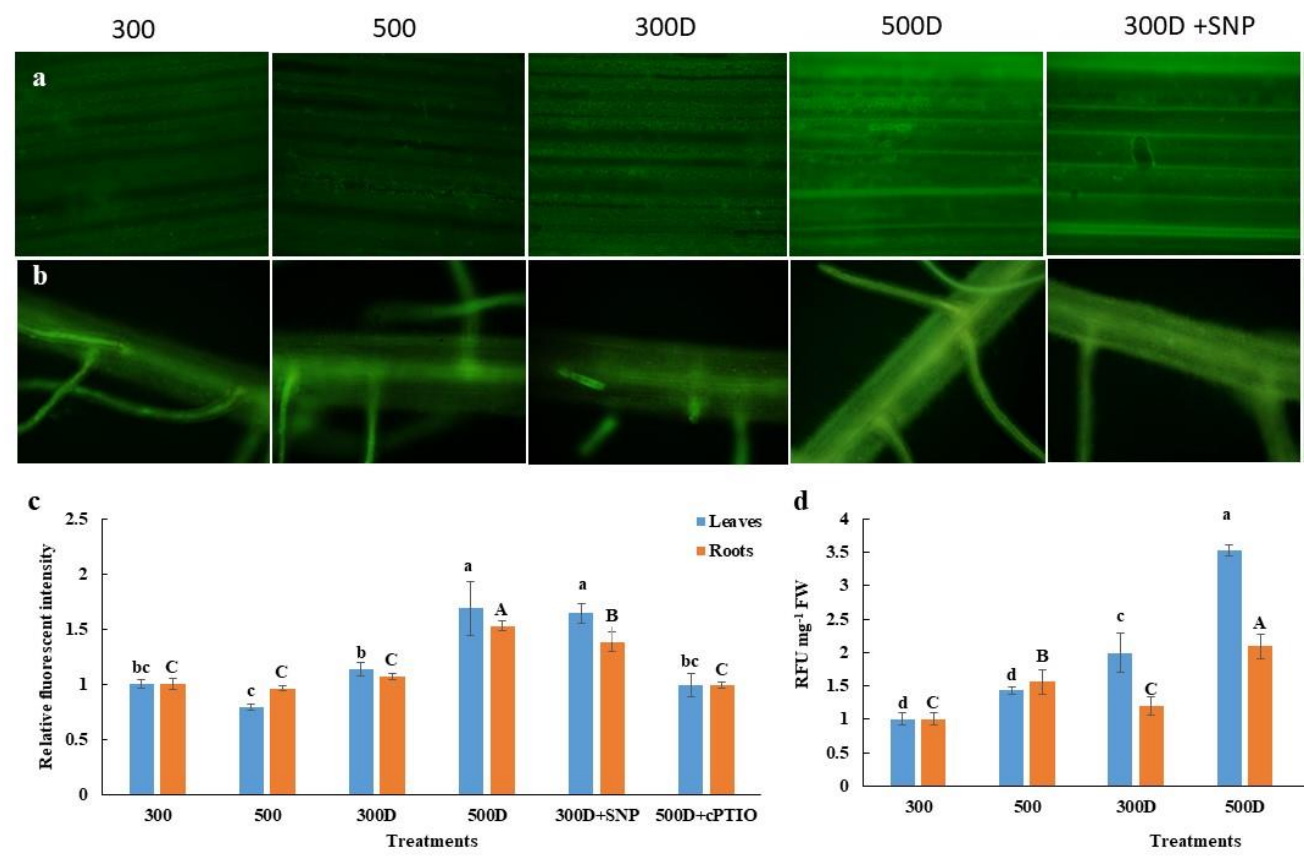

$500 \mathrm{D}+\mathrm{cPTIO}$

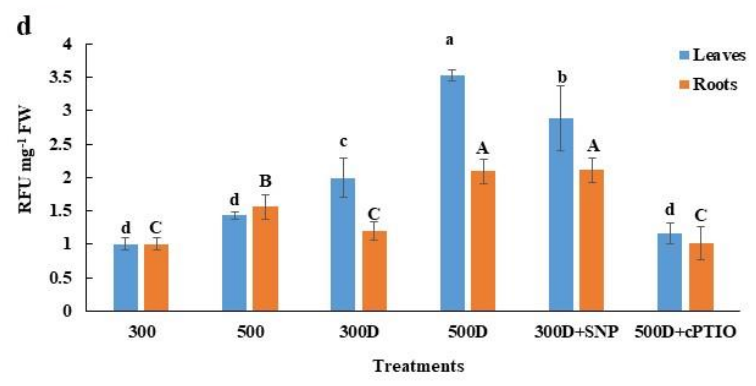

Figure 5. Reactive nitrogen species accumulation responses. The epifluorescent images of rice (a) leaves and (b) roots after 1-h incubation in $20 \mu \mathrm{M}$ DAF-FM DA. The plants were subjected to the different NO-associated treatments for 3 . days: $300 \mathrm{mg} \mathrm{L}^{-1} \mathrm{~N}$-primed (300C); $500 \mathrm{mg} \mathrm{L}^{-1} \mathrm{~N}$-primed (500C); $300 \mathrm{mg} \mathrm{L}^{-1} \mathrm{~N}$-primed with PEG water deficit induction (300D); $500 \mathrm{mg} \mathrm{L}^{-1} \mathrm{~N}$-primed with PEG water deficit induction (500D); $300 \mathrm{mg} \mathrm{L}^{-1} \mathrm{~N}$-primed with PEG water deficit induction + Nitric oxide donor (300D + sodium nitroprussiate-SNP); $500 \mathrm{mg} \mathrm{L}^{-1} \mathrm{~N}$-primed with PEG water deficit induction + Nitric oxide scavenger (500D + cPTIO) (c) Relative fluorescent intensity of the histochemical nitric oxide (NO) accumulation of the leaves and roots (d) Relative fluorescent units (RFUs) of the released NO after 2-h incubation in $7 \mu$ M DAF-FM. Values shown are the Mean \pm SE ( $n \geq 30$ and $n=4$, respectively). The different letters above the bars indicate significant differences by one-way ANOVA and Duncan's test $(p \leq 0.05)$, and the small letters represent the statistics of the leaves and the capital letters represent the statistics of the roots.

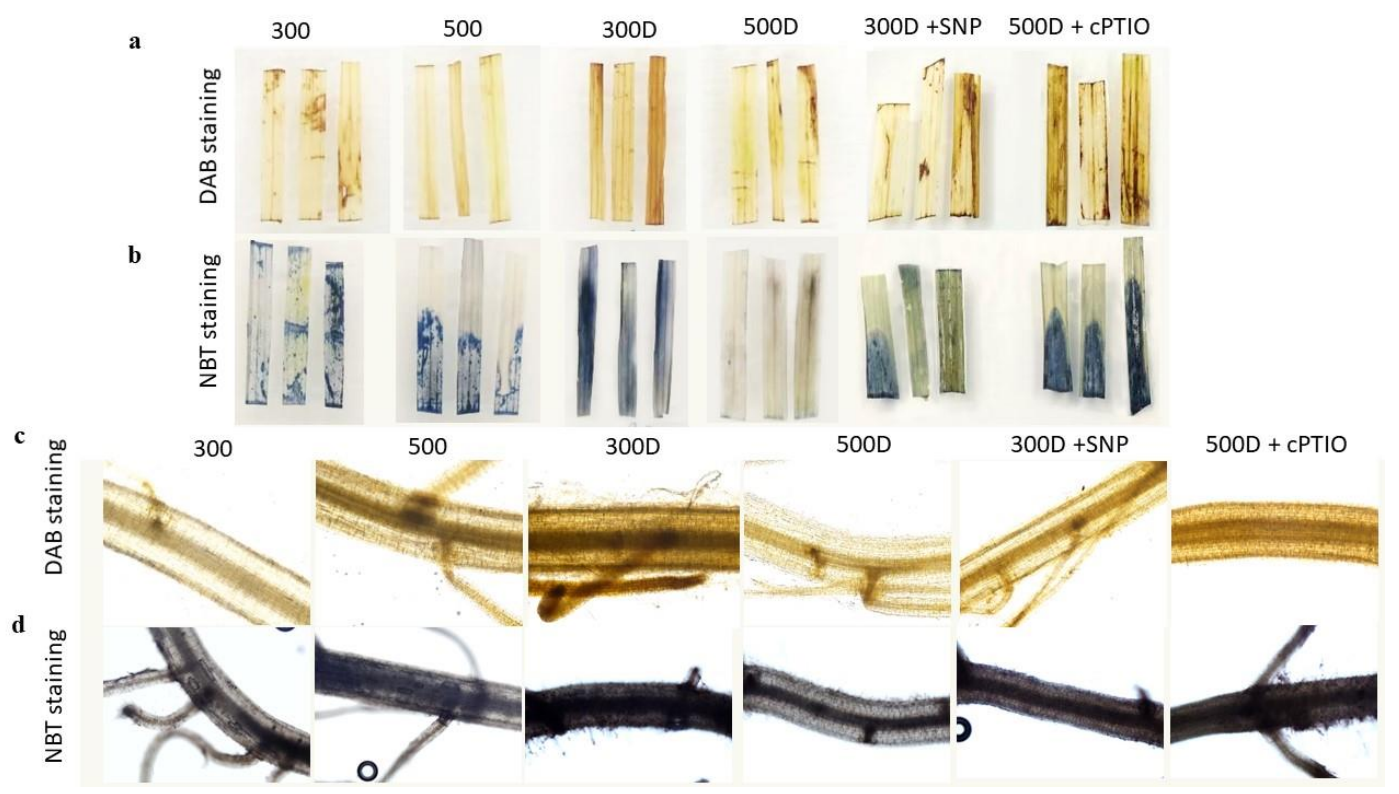

Figure 6. Reactive oxygen species accumulation responses. Hydrogen peroxide accumulation detected by 3,3'diaminobenzidine (DAB) staining of (a) leaves and (c) roots. Superoxide radical accumulation detected by nitro blue tetrazolium (NBT) staining of $(\mathbf{b})$ leaves and (d) roots of rice plants after 3-day growth in the different NO-associated treatments. 

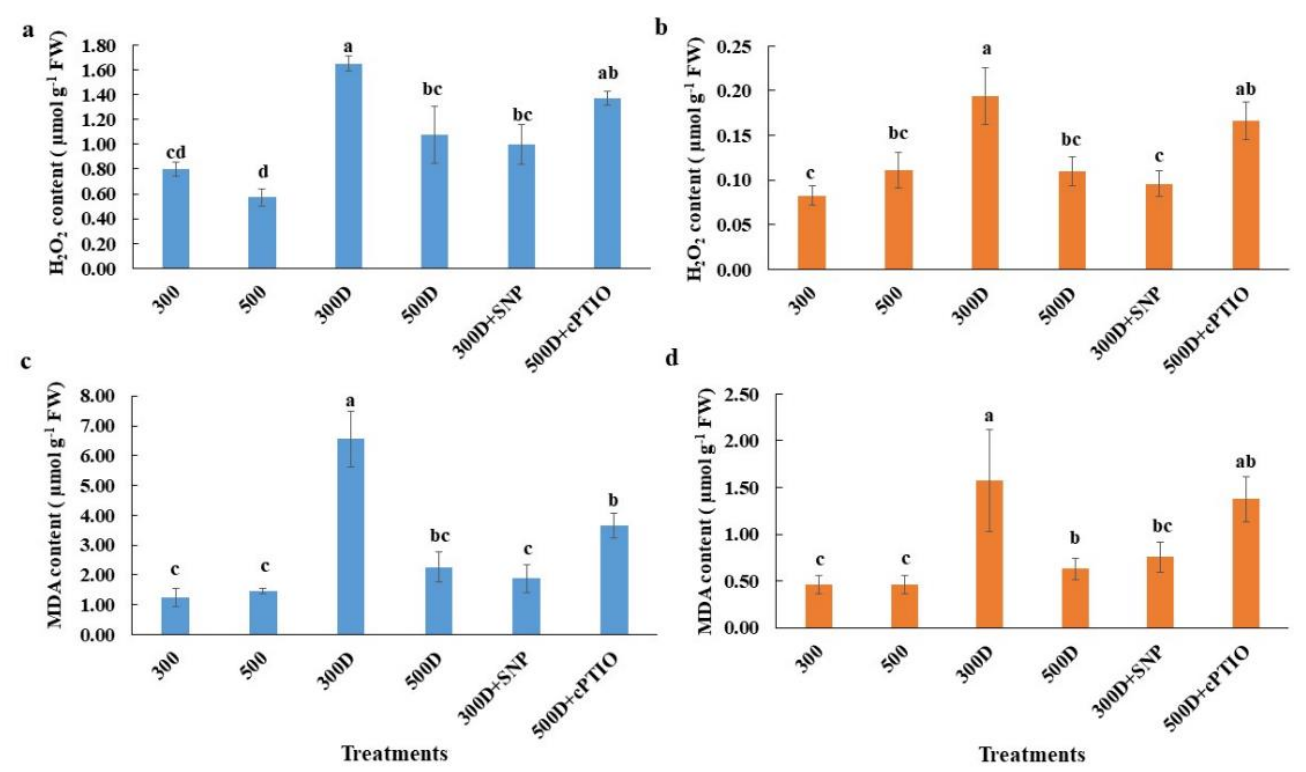

Figure 7. Quantitative ROS accumulation and lipid peroxidation responses: quantitative hydrogen peroxide accumulation in (a) leaves and (b) roots, and malondialdehyde (MDA) content of (c) leaves and (d) roots of rice plants after 3-day growth in the different NO-associated treatments. Values shown are the Mean \pm SE $(n=4)$. The different letters above the bars indicate significant differences by one-way ANOVA and Duncan's test ( $p \leq 0.05)$.

\section{Discussion}

Nitrogen is an essential nutrient that plays the main role in leaf development. In many cases, high nitrogen application induced leaf area increment and total plant transpiration increment while $\mathrm{N}$ also increases root growth, leading to the added water and nutrient uptakes to support the increased transpiration and maintain high photosynthetic activity and chloroplast functions during water deficit conditions [23]. However, high nitrogen priming during a short period of nitrogen application effects were first investigated here (prior to drought episodes). We found rice plants primed with $500 \mathrm{mg} \mathrm{L}^{-1} \mathrm{~N}$ prior to water deficit conditions maintained higher photosynthetic rates (Figure 1a) but did not alter the transpiration rate (Figure 2c), resulting in a dramatic increase in instantaneous water use efficiency (Figure 2d). Elevated nitrogen priming in our studies also induced plant responses similar to the high soil-incorporated nitrogen application [20,21]. Haefele et al. [24] and Zhong et al. [25] both suggested the use of high nitrogen fertilizer increases water-use efficiency, drought tolerance and survival rates for $\mathrm{C} 3$ and $\mathrm{C} 4$ crops. The improvement of photosynthetic capacity mainly depended on the activity of ribulose-1,5-bisphosphate carboxylase (Rubisco). Around 15 to 30\% of leaf nitrogen are invested in Rubisco [26]. The high nitrogen levels induced higher Rubisco content, which was generally degraded during stress episodes [27]. The elevated N-primed rice might delay the degradation of Rubisco and maintain a high photosynthetic rate under water deficit conditions, as well as less sensitive stomatal behavior $[24,25]$. The maintenance of relative water content in elevated $\mathrm{N}$-primed plants may be explained by the accumulation of $\mathrm{NO}$ as shown in Li et al. 2013 where the NO donor could have induced fructans accumulation, which resulted in plant cell water content regulation [12].

On the other hand, Gao et al. 2019 indicated that low nitrogen priming levels reduced the transpiration rate, stomatal conductance and maintained a higher leaf relative water content to mitigate drought-induced damage [28]. We also found slightly lower transpiration rates (Figure 2c) and significantly higher leaf relative water content (Figure 2a) in $100 \mathrm{mg} \mathrm{L}^{-1}-\mathrm{N}$ primed plants. Low nitrogen priming may also have induced lower chlorophyll and protein content, slowing down the process of stress recovery [29]. 
Although elevated $\mathrm{N}\left(500 \mathrm{mg} \mathrm{L}^{-1}-\mathrm{N}\right)$ priming benefits the tolerance of rice plants, excessive $\mathrm{N}\left(1000 \mathrm{mg} \mathrm{L}^{-1}-\mathrm{N}\right)$ priming leads to stress symptoms, like decreasing photosynthetic activity (Figure 1a), lower RWC (Figure 2a) and higher electrolyte leakage (Figure 3c), compared to plants primed with $500 \mathrm{mg} \mathrm{L}^{-1} \mathrm{~N}$ under control conditions. Excessive nitrogen application can also generate an imbalance in the carbon/nitrogen ratio which causes mature leaf senescence, leading to yield reduction after drought episodes [30]. Excessive nitrogen has impacts on the antioxidant defense systems in wheat [31], and in our study (Figure 4). Many nonenzymatic antioxidant molecules, such as GABA, 4-hydroxybenzoylcholine and several phenolic compounds were downregulated in the leaves of rice plants grown under excessive N, which led to the overaccumulation of ROS [31].

Redox imbalance under water deficit conditions is accountable for significant plant cell damage. The antioxidant induction system is a viable approach to alleviate cellular damage and a higher tolerability of plants to water deficit conditions [10,32,33]. We observed enhanced antioxidant enzyme activity in $500 \mathrm{mg} \mathrm{L}^{-1} \mathrm{~N}$ primed rice (Figures 1a and 2a). Perhaps the one-day elevated $\mathrm{N}$ priming was sufficient to activate antioxidant systems. Five-hundred $\mathrm{mg} \mathrm{L}^{-1} \mathrm{~N}$ priming reduced membrane damage as demonstrated by the lower electrolyte leakage (Figure 3c) and MDA content (Figure 7d), which were supported by increasing SOD and APX activities (Figure 4a,c). Antioxidant defense systems act as drought tolerance mechanisms in many crop species, including rice, creeping bentgrass (Agrostis stolonifera L.), wheat (Triticum aestivum L.) seedlings and peanuts (Arachis hypogaea L.) [34-38].

The antioxidant defense system that controls ROS status in plant cells has also been reported to be regulated by the level of reactive nitrogen species (RNS) from both endogenous production and exogenous application [8,9,35,36,39]. Cai et al. 2015 [9] found that the overexpression of rat neuronal NO synthase (nNOS) in rice enhanced drought and salt tolerance of rice with a higher NOS activity and the accumulation of NO, together with a reduction in $\mathrm{H}_{2} \mathrm{O}_{2}$ accumulation, electrolyte leakage and MDA content. Using $\mathrm{NO}$ donors, SNP as a seed priming solution and foliar spray has previously induced rice drought tolerance in rice [13]. Because $\mathrm{NO}$ acts as a signaling molecule it can enhance antioxidant capacity thus reducing oxidative damage [13]. The $500 \mathrm{mg} \mathrm{L}^{-1} \mathrm{~N}$ leaves and roots accumulated higher endogenous $\mathrm{NO}$ and released $\mathrm{NO}$, which was inhibited by the NO scavenger, $\mathrm{cPTIO}$ (Figure $5 \mathrm{~b}-\mathrm{d}$ ). The level of NO accumulation was close to that of the normal N-primed ( $300 \mathrm{mg} \mathrm{L}^{-1} \mathrm{~N}$ ) plants supplied with $1 \mathrm{mM} \mathrm{SNP}$ (Figure $5 \mathrm{~b}$,d). In contrast, $500 \mathrm{mg} \mathrm{L}^{-1} \mathrm{~N}$ primed plants possessed less $\mathrm{O}_{2}{ }^{\bullet-}$ and $\mathrm{H}_{2} \mathrm{O}_{2}$ accumulation evidenced by the NBT, DAB staining and $\mathrm{H}_{2} \mathrm{O}_{2}$ quantification (Figures 6 and $7 \mathrm{a}, \mathrm{b}$ ). We measured only $\mathrm{O}_{2}{ }^{\bullet-}$ and $\mathrm{H}_{2} \mathrm{O}_{2}$ because these two species have been reported to directly interact with NO [40,41]. Adding cPTIO may mitigate such effects (Figures 6 and 7a,b). Control plants ( $300 \mathrm{mg} \mathrm{L}^{-1} \mathrm{~N}$ ) had less $\mathrm{O}_{2}{ }^{\bullet-}$ and $\mathrm{H}_{2} \mathrm{O}_{2}$ further suggesting a relationship between elevated $\mathrm{N}$ priming and increased NO (Figures 6 and $7 \mathrm{a}, \mathrm{b}$ ). This phenomenon might be explained by the fact that NO in plants can be generated by NO synthase (NOS), nitrate reductase (NR) and xanthine oxidoreductase [10]. When priming rice with elevated $\mathrm{N}$, it induced NR activity, promoting greater nitrite levels (precursors for both NO production and N assimilation [42]. Higher NO levels in elevated N-primed rice promoted the antioxidant defense system, causing less accumulated ROS and less oxidative damage while maintaining photosynthetic functions. NO acted as a potent inhibitor of lipid peroxidation by scavenging lipid alcoxyl ( $\mathrm{LO}^{\circ}$ ) and peroxyl ( $\mathrm{LOO}^{*}$ ) radicals [43]. $\mathrm{NO}$ also directly quenches the ROS, such as superoxide radical $\left(\mathrm{O}_{2}{ }^{--}\right)$[44], limits oxidative damage and prevents the onset of cell death [45]. Moreover, NO maintained membrane fluidness, cell wall relaxation, cell enlargement and plant growth under stressful conditions [11,42]. Therefore, elevated nitrogen priming demonstrated a water deficit tolerance through NO-mediated antioxidant defense mechanisms. 


\section{Materials and Methods}

\subsection{Plant Material and Greenhouse Growth Conditions}

Seeds of Thai rice (Oryza sativa L. subspecies indica cv. Pathumthani 1) were germinated on moist germination paper for $10 \mathrm{~d}$ at $28^{\circ} \mathrm{C}$ in the dark. Seedlings were transplanted into 2-L pots filled with 1:1 vermiculite: perlite. The seedlings were grown in the greenhouse with day lengths of $11-12 \mathrm{~h}$ and daily average temperatures of $35 \pm 4 / 24 \pm 7^{\circ} \mathrm{C}$ day/night and 700-1500 $\mu \mathrm{mol} \mathrm{m}^{-2} \mathrm{~s}^{-1}$ mid-day photosynthetically active radiation (PAR). Plants were fertilized every other day with ( $\mathrm{N} 300 \mathrm{mg} \mathrm{L}^{-1}$ equal in nitrate and ammonium forms), P $20 \mathrm{mg} \mathrm{L}^{-1}$, $\mathrm{K}_{75} \mathrm{mg} \mathrm{L}^{-1}$, Ca $25 \mathrm{mg} \mathrm{L}^{-1}, \mathrm{Mg}_{17} \mathrm{mg} \mathrm{L}^{-1}, \mathrm{~S} 55 \mathrm{mg} \mathrm{L}^{-1}$, Fe $3.30 \mathrm{mg} \mathrm{L}^{-1}$, Mn $0.50 \mathrm{mg} \mathrm{L}^{-1}$, Zn $0.05 \mathrm{mg} \mathrm{L}^{-1}$, Mo $0.01 \mathrm{mg} \mathrm{L}^{-1}, \mathrm{Cu} 0.02 \mathrm{mg} \mathrm{L}^{-1}$ ) for 10 weeks until the plants were one week before panicle initiation. Then, different concentrations of nitrogen $(\mathrm{N})$ fertilizer were applied by using $\mathrm{N} 100 \mathrm{mg} \mathrm{L}^{-1}$ (equal in nitrate and ammonium forms), P $20 \mathrm{mg} \mathrm{L}^{-1}$, $\mathrm{K} 75 \mathrm{mg} \mathrm{L}^{-1}$, Ca $25 \mathrm{mg} \mathrm{L}^{-1}, \mathrm{Mg} 17 \mathrm{mg} \mathrm{L}^{-1}$, S $55 \mathrm{mg} \mathrm{L}^{-1}$, Fe $3.30 \mathrm{mg} \mathrm{L}^{-1}$, Mn $0.50 \mathrm{mg} \mathrm{L}^{-1}$, Zn $0.05 \mathrm{mg} \mathrm{L}^{-1}$, Mo $0.01 \mathrm{mg} \mathrm{L}^{-1}$, Cu $0.02 \mathrm{mg} \mathrm{L}^{-1}$ as base fertilizer and added ammonium nitrate $\left(\mathrm{NH}_{4} \mathrm{NO}_{3}\right)$ to reach target concentrations of 300, 500 and $1000 \mathrm{mg} \mathrm{L}^{-1} \mathrm{~N}$ and used double volume of the field capacity of the pots to wash the previous nitrogen fertilizer. Water deficit stress was applied by withholding water for $\sim 7 \mathrm{~d}$ when visual stress symptoms (i.e., leaf rolling) appeared (10-15\% relative soil water content) [7], when the gas exchange parameters were measured and the leaf samples were taken for biochemical assays. The leaves were collected between $9.00 \mathrm{am}$ and $11.00 \mathrm{am}$ and immediately frozen in liquid nitrogen and kept at $-80{ }^{\circ} \mathrm{C}$ until use.

\subsection{Gas-Exchange Measurements}

Net photosynthetic rate and stomatal conductance were measured with the photosynthesis system ADC LCi-SD (BioScientific, UK). The measurements were conducted under $900 \pm 50 \mu \mathrm{mol} \mathrm{m}^{-2} \mathrm{~s}^{-1}$ light intensity and $380 \pm 10 \mu \mathrm{mol} \mathrm{mol}^{-1} \mathrm{CO}_{2}$ surrounding the leaf (Ca) at $32 \pm 2{ }^{\circ} \mathrm{C}$. To calculate instantaneous transpiration, the transpiration rate was divided by the net photosynthetic rate.

\subsection{Leaf Area}

After one-day post recovery, all remaining leaves were removed and all surface dust was wiped away prior to measuring the area with an LI-3100C area meter (LI-COR, Lincoln, NE, USA) in square centimeters.

\subsection{Relative Water Content (RWC) of Leaves}

RWC was determined according to Gao et al. 2019 [28]. Leaves were weighed immediately to obtain fresh weight (FW), soaked in water overnight in the dark and weighed again to obtain turgid fresh weight (TW), and then dried at $75^{\circ} \mathrm{C}$ until constant weight (DW). RWC was then calculated as follows:

$$
\mathrm{RWC}=(\mathrm{FW}-\mathrm{DW}) /(\mathrm{TW}-\mathrm{DW})
$$

\subsection{Electrolyte Leakage (EL)}

The electrolyte leakage measurement was adjusted based on the method described previously by Cai et al. 2015 [9]. After placing six $1 \mathrm{~cm}^{2}$ leaves from each treatment into a 50-mL-tube with $20 \mathrm{~mL}$ distilled deionized water, the tubes were shaken and electroconductivity $\left(E C_{i}\right)$ was immediately measured with a $\mathrm{pH} /$ cond meter (WTW, inoLab, Germany). After soaking the leaves for $12 \mathrm{~h}$, the second conductivity was measured $\left(E C_{f}\right)$. Then, the leaves were boiled for $1 \mathrm{~h}$ and the total electro-conductivity was measured $\left(E C_{t}\right)$. The electrolyte leakage was calculated as follows:

$$
\% \mathrm{EL}=\left(\frac{E C_{f}-E C_{i}}{E C_{t}-E C_{i}}\right) \times 100
$$




\subsection{Determining SOD, CAT and APX Activities}

Enzymes were extracted by the modified method of Umnajkitikorn et al. 2013 [46]. The frozen leaves were ground in liquid nitrogen with a mortar and pestle. Two hundred fifty $\mathrm{mg}$ of the leaf powder were homogenized in $1 \mathrm{~mL}$ of the extraction buffer containing $50 \mathrm{mM}$ potassium phosphate buffer (pH 7.8), $0.1 \mathrm{mM}$ disodium EDTA, $1 \mathrm{mM}$ ascorbic acid and, $2 \% \operatorname{PVPP}(w / v)$. The homogenate was centrifuged at $15,000 \times g$ for $20 \mathrm{~min}$ at $4{ }^{\circ} \mathrm{C}$. The supernatant was collected for SOD, CAT and APX activity assays.

SOD activity was assayed based on the method described by Beauchamp and Fridovich 1971 [47] and Vaidyanathan et al. 2003 [48]. One point two milliliters of the reaction mixture, containing $50 \mathrm{mM}$ sodium phosphate buffer (pH 7.8), $10 \mathrm{mM}$ EDTA, $1 \mathrm{mM} \mathrm{NBT}, 5 \mathrm{mM}$ L-methionine, $0.2 \mathrm{mM}$ riboflavin and mixed with $80 \mu \mathrm{L}$ of extracts. Each reaction was carried out at $25 \pm 2{ }^{\circ} \mathrm{C}$ under a light intensity, which is sufficient to increase absorbance of $0.110 / 10 \mathrm{~min}$ (in the absence of the enzyme) for $30 \mathrm{~min}$. Two hundred microliters of the reactions were taken to Nunc microwell 96-well plate (Thermo ScientificTM, Shanghai, China) for the absorbance at $560 \mathrm{~nm}$ (A560), using spectrophotometer (Biotex, Epoch, Winooski, VT, USA). The nonirradiated reaction mixture served as a blank and was deducted from A560. One unit of SOD activity was defined as the amount of enzyme required to inhibit the reduction of NBT by $50 \%$.

CAT activity was assayed based on the method of Sunohara and Matsumoto 2004 [49]. One hundred and ninety microliters of the assay mixture contained $20 \mathrm{mM} \mathrm{H}_{2} \mathrm{O}_{2}$ in $50 \mathrm{mM}$ potassium phosphate buffer ( $\mathrm{pH} 7.0$ ), $0.1 \mathrm{mM}$ disodium-EDTA and $10 \mu \mathrm{L}$ of extracts. The reactions were carried in Nunc 96 well UV transparent plate (Thermo ScientificTM, Vantaa, Finland). The absorbance was measured at $240 \mathrm{~nm}$ with a UV/VIS spectrophotometer (Biotex, Epoch, Winooski, VT, USA). The enzyme activity was defined as the amount of $\mathrm{H}_{2} \mathrm{O}_{2}$ decomposed $\mathrm{min}^{-1} \mathrm{mg}$ protein ${ }^{-1}$. The molar coefficient of $\mathrm{H}_{2} \mathrm{O}_{2}$ (E) is $39.4 \mathrm{M}^{-1} \mathrm{~cm}^{-1}$ ) at $240 \mathrm{~nm}$.

APX activity was assayed based on the method of Sunohara and Matsumoto 2004 [49]. One hundred and eighty microliters of the assay mixture contained $120 \mu \mathrm{L}$ of $50 \mathrm{mM}$ potassium phosphate buffer (pH 7.0), $20 \mu \mathrm{L}$ of $1 \mathrm{mM}$ EDTA, $20 \mu \mathrm{L}$ of $5 \mathrm{mM}$ L-ascorbic acid, $20 \mu \mathrm{L}$ of $1 \mathrm{mM} \mathrm{H}_{2} \mathrm{O}_{2}$ and $20 \mu \mathrm{L}$ of extracts. The subsequent decrease in ascorbic acid was observed at $290 \mathrm{~nm}\left(\mathrm{E}=2.8 \mathrm{mM}^{-1} \mathrm{~cm}^{-1}\right.$ ) with a UV/VIS spectrophotometer (Biotex, Epoch, Winooski, VT, USA). The enzyme activity was defined as the amount of ascorbic acid (ASA) which decomposed $\mathrm{min}^{-1} \mathrm{mg}_{\text {protein }}{ }^{-1}$.

\subsection{Protein Quantification}

The Bradford assay [50] was used for protein quantification using bovine serum albumin as the standard.

\subsection{The RNS and ROS Experiment}

Rice seeds (Oryza sativa subspecies indica cv. Pathumthani 1) were germinated and grown for $5 \mathrm{~d}$ at $25^{\circ} \mathrm{C}$ in darkness. Seedlings were transplanted into $9-\mathrm{cm}$ pots filled with vermiculite 4 plants/pot and grown in the growth room with $12 \mathrm{~h} / 12 \mathrm{~h}$ light/dark cycles and $25 / 20^{\circ} \mathrm{C}$ day/night cycles for 3 weeks with fertilizer containing $300 \mathrm{mg} \mathrm{L}^{-1} \mathrm{~N}$. Then, the plants were randomly divided into 6 groups and transferred to glass tubes with the following treatments: (1) $300 \mathrm{mg} \mathrm{L}^{-1} \mathrm{~N}$ (300 C); (2) $500 \mathrm{mg} \mathrm{L}^{-1}$ a day and switched back to the $300 \mathrm{mg} \mathrm{L}^{-1}$ (500 C); (3) $300 \mathrm{mg} \mathrm{L}^{-1} \mathrm{~N}$ + gradually increased polyethylene glycol (PEG) 6000 (300 D); (4) $500 \mathrm{mg} \mathrm{L}^{-1}$ a day and switched back to the $300 \mathrm{mg} \mathrm{L}^{-1}+$ gradually increased PEG (500 D); (5) $300 \mathrm{mg} \mathrm{L}^{-1} \mathrm{~N}+$ PEG 6000 + nitric oxide donor, $1 \mathrm{mM}$ SNP (300 D + SNP); (6) $500 \mathrm{mg} \mathrm{L}^{-1} \mathrm{~N}+$ PEG $6000+3 \mathrm{mM}$ of Nitric oxide scavenger, 2-(4carboxyphenyl)-4,4,5,5-tetramethylimidazoline-1-oxyl-3-oxide (cPTIO) (500 D + cPTIO). After 3 days under each treatment, the seedlings were harvested for further ROS and RNS analyses. 


\subsection{NO Determination}

To histologically detect NO, the leaf and root segments were soaked for $1 \mathrm{~h}$ with

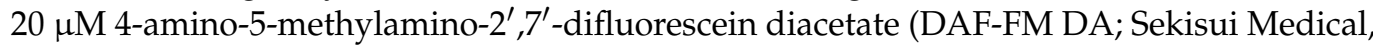
Tokyo, Japan). The epifluorescence images were captured with an Eclipse 90i microscope (Nikon, Tokyo, Japan). The intensity of the fluorescent signal from at least 30 pictures of each treatment was quantified by using Image J software (by Wayne Rasband, NIH, MD, USA).

The concentration of NO released from the roots was assessed in leaf and root segments of the seedlings in each treatment after incubation in $7 \mu \mathrm{M}$ DAF-FM for $2 \mathrm{~h}$. The fluorescence intensity of the DAF-FM solution was measured as described in Fukudome et al. 2016 [51] but adapted by adding $100 \mu \mathrm{L}$ of the solution into the 96 well black plate (SPL life sciences, Gyeonggi-do, Korea), then measured with a fluorescence spectrophotometer (Varioskan Lux, Finland) at $495 \mathrm{~nm}$ and $519 \mathrm{~nm}$ as excitation and emission wavelengths, respectively. The released NO was expressed as relative fluorescence units (RFUs) per fresh weight of leaves or roots.

\subsection{Histochemical Detection of $\mathrm{H}_{2} \mathrm{O}_{2}$ and $\mathrm{O}_{2}{ }^{\bullet-}$}

$\mathrm{H}_{2} \mathrm{O}_{2}$ was detected in situ according to Fukudome et al. 2019 [39] and Signorelli et al. 2013 [52]. Detached leaves and roots were vacuum-infiltrated in the dark with $10 \mathrm{mM}$ potassium phosphate buffer, and $0.1 \%(w / v)$ 3,3'-diaminobenzidine (DAB), at $\mathrm{pH}$ 7.8. Samples were incubated overnight in the dark. The leaf segments were boiled in $95 \%$ ethanol at $90 \mathrm{oC}$ to remove chlorophyll. The clear leaf segments were then photographed. The staining areas were calculated by Image J software (by Wayne Rasband, NIH, USA), in the red channel according to procedure described in [53]. Data were shown in Supplementary Figure S2. The detailed method of staining area identification is given in Supplementary file 2.

Superoxide radical $\left(\mathrm{O}_{2}{ }^{\bullet-}\right)$ was detected in situ essentially as described by to Fukudome et al. 2019 [39] and Signorelli et al. 2013 [52]. Detached leaves and roots were vacuum-infiltrated with $10 \mathrm{mM}$ potassium phosphate buffer, $0.1 \%(w / v)$ nitro blue tetrazolium (NBT), and $0.05 \%(v / v)$ Tween $20, \mathrm{pH} 7.8$. Treated samples were incubated overnight in the dark, cleared and photographed as described above. The staining areas were calculated by Image J software (by Wayne Rasband, NIH, MD, USA), in the blue channel according to the procedure described in [53]. Data are shown in Supplementary Figure S2.

\subsection{1. $\mathrm{H}_{2} \mathrm{O}_{2}$ Quantification}

The frozen leaves were ground and $5-10 \mathrm{mg}$ of samples were extracted with $1 \mathrm{~mL}$ of $20 \mathrm{mM} \mathrm{K}_{2} \mathrm{HPO}_{4}(\mathrm{pH} 6.5)$, homogenized at $1500 \mathrm{rpm}$ for $5 \mathrm{~min}$ at $4{ }^{\circ} \mathrm{C}$ and then centrifuged for 5 min at $16,200 \times g$ at $4{ }^{\circ} \mathrm{C}$. The $\mathrm{H}_{2} \mathrm{O}_{2}$ was colorimetrically quantified by Amplex Red detection assay (Thermo Fisher Scientific). The measurement was performed on the supernatant as described in Brumbarova et al. 2016 [54] with some modification of the incubation time from $30 \mathrm{~min}$ to $15 \mathrm{~min}$. The assay solutions were analyzed at $560 \mathrm{~nm}$ with a UV/VIS spectrophotometer (Biotex, Epoch, Winooski, VT, USA). The standard curve was also generated with $\mathrm{H}_{2} \mathrm{O}_{2}$ concentration from $0-5 \mu \mathrm{M}$.

\subsection{Malondialdehyde (MDA) Measurements}

The youngest fully expanded leaves were homogenized with $5 \mathrm{~mL}$ of $50 \mathrm{mM}$ potassium phosphate buffer $\mathrm{pH} 7.5$ and centrifuged at $20,000 \times \mathrm{g}$ for $25 \mathrm{~min}$. For measurements of MDA concentration, $4 \mathrm{~mL}$ of $20 \%$ trichloroacetic acid containing $0.5 \%$ thiobarbituric acid were added to a $1 \mathrm{~mL}$ aliquot of the supernatant. The mixture was heated at $95^{\circ} \mathrm{C}$ for $30 \mathrm{~min}$, quickly cooled in ice and then centrifuged at $10,000 \times \mathrm{g}$ for $10 \mathrm{~min}$. The absorbance of the supernatant was measured at $532 \mathrm{~nm}$. The results are shown as MDA content $\mathrm{mg}^{-1}$ FW, using malondialdehyde tetrabutylammonium salt as a standard (Sigma-Aldrich, Cat 63287, Singapore). 


\subsection{Statistical Analysis}

The SPSS 25 statistical package was used for statistical analyses. The experiments were based on a randomized complete block design.

\section{Conclusions}

Elevated $\mathrm{N}$ priming at approximately $60 \%$ more than normal $\mathrm{N}$ level enhanced water deficit tolerance with NO-triggered antioxidant defense systems. The elevated $\mathrm{N}$ priming also supported the sustainability of photosynthetic activity and relative water contentof the leaves, together with the reduction of membrane damage. This approach has potential for in-situ investigation in aerobic rice fields with fertigation systems as a potential mitigating factor for enhancing drought tolerance in rice.

Supplementary Materials: The following are available online at https://www.mdpi.com/2223-774 7/10/2/381/s1, Supplementary file 1: Fertilizer Information and Formulation sheet. Supplementary file 2: Figure S1: Examples of the picture calibrated for staining area evaluation. Figure S2: The ROS staining area of tissue segments of rice plants after 3-day growth in the different NO-associated treatments; Procedure for staining area quantification by image J.

Author Contributions: Experiment planning, K.U. and T.U.; Performing experiments K.U. and M.F.; Statistical analyses and data interpretation, K.U.; Manuscript preparation, K.U., M.F., T.U and N.T. All authors have read and agreed to the published version of the manuscript.

Funding: This work was supported by Suranaree University of Technology (SUT), Thailand.

Institutional Review Board Statement: Not applicable.

Informed Consent Statement: Not applicable.

Data Availability Statement: Data available in a publicly accessible repository.

Acknowledgments: The authors would like to thank Colin T. Strine, School of Biology, Institute of Science, Suranaree University of Technology, for English corrections in this manuscript.

Conflicts of Interest: The authors declare that there is no conflict of interest.

\section{References}

1. Leng, G.; Hall, J. Crop yield sensitivity of global major agricultural countries to droughts and the projected changes in the future. Sci. Total Environ. 2019, 654, 811-821. [CrossRef]

2. Bodner, G.; Nakhforoosh, A.; Kaul, H.P. Management of crop water under drought: A review. Agron. Sustain. Dev. 2015, 35, 401-442. [CrossRef]

3. Oladosu, Y.; Rafii, M.Y.; Samuel, C.; Fatai, A.; Magaji, U. Drought Resistance in Rice from Conventional to Molecular Breeding: A Review. Int. J. Mol. Sci. 2019, 20, 3519. [CrossRef]

4. Shavrukov, Y.; Kurishbayev, A.; Jatayev, S.; Shvidchenko, V.; Zotova, L.; Koekemoer, F.; Groot, S.; De Soole, K.; Lan-gridge, P. Early Flowering as a Drought Escape Mechanism in Plants: How Can It Aid Wheat Production? Front. Plant Sci. 2017, 8, 1-8. [CrossRef] [PubMed]

5. Sade, N.; del Mar Rubio-Wilhelmi, M.; Umnajkitikorn, K.; Blumwald, E. Stress-induced senescence and plant tolerance to abiotic stress. J. Exp. Bot. 2017, 69, 1-9. [CrossRef] [PubMed]

6. Fahad, S.; Bajwa, A.A.; Nazir, U.; Anjum, S.A.; Farooq, A.; Zohaib, A.; Sadia, S.; Nasim, W.; Adkins, S.; Saud, S.; et al. Crop production under drought and heat stress: Plant responses and management options. Front. Plant Sci. 2017, 8, 1-16. [CrossRef]

7. Sade, N.; Umnajkitikorn, K.; Wilhelmi, M.d.M.R.; Wright, M.; Wang, S.; Blumwald, E. Delaying chloroplast turn-over increases water-deficit stress tolerance through the enhancement of nitrogen assimilation in rice. J. Exp. Bot. 2017, 69, 867-878. [CrossRef]

8. Nabi, R.B.S.; Tayade, R.; Hussain, A.; Kulkarni, K.P.; Imran, Q.M.; Mun, B.G.; Yun, B.W. Nitric oxide regulates plant re-sponses to drought, salinity, and heavy metal stress. Environ. Exp. Bot. 2019, 161, 120-133. [CrossRef]

9. Cai, W.; Liu, W.; Wang, W.; Fu, Z.; Han, T.; Lu, Y. Overexpression of Rat Neurons Nitric Oxide Synthase in Rice En-hances Drought and Salt Tolerance. PLoS ONE 2015, 10, e0131599. [CrossRef]

10. Groß, F.; Durner, J.; Gaupels, F. Nitric oxide, antioxidants and prooxidants in plant defence responses. Front. Plant Sci. 2013, 4, 1-15. [CrossRef]

11. Ahmad, P.; Latef, A.A.A.; Hashem, A.; Abd Allah, E.F.; Gucel, S.; Tran, L.S.P. Nitric oxide mitigates salt stress by regu-lating levels of osmolytes and antioxidant enzymes in chickpea. Front. Plant Sci. 2016, 7, 1-11. [CrossRef]

12. Li, C.; Li, T.; Zhang, D.; Jiang, L.; Shao, Y. Exogenous nitric oxide effect on fructan accumulation and FBEs expression in chilling-sensitive and chilling-resistant wheat. Environ. Exp. Bot. 2013, 86, 2-8. [CrossRef] 
13. Farooq, M.; Basra, S.M.A.; Wahid, A.; Rehman, H. Exogenously Applied Nitric Oxide Enhances the Drought Tolerance in Fine Grain Aromatic Rice (Oryza sativa L.). J. Agron. Crop Sci. 2009, 195, 254-261. [CrossRef]

14. Wildt, J.; Kley, D.; Rockel, A.; Rockel, P.; Segschneide, H.J. Emission of NO from several higher plant species. J. Geophys. Res. 1997, 102, 5919-5927. [CrossRef]

15. Tejada-jimenez, M.; Llamas, A.; Galv, A.; Fern, E. Photosynthetic Eukaryotes. Plants 2019, 8, 56. [CrossRef]

16. Sun, H.; Li, J.; Song, W.; Tao, J.; Huang, S.; Chen, S.; Hou, M.; Xu, G.; Zhang, Y. Nitric oxide generated by nitrate re-ductase increases nitrogen uptake capacity by inducing lateral root formation and inorganic nitrogen uptake under par-tial nitrate nutrition in rice. J. Exp. Bot. 2015, 66, 2449-2459. [CrossRef]

17. Cao, X.; Zhong, C.; Sajid, H.; Zhu, L. Effects of watering regime and nitrogen application rate on the photosynthetic parameters, physiological characteristics, and agronomic traits of rice. Acta Physiol. Plant. 2017, 39, 1-12. [CrossRef]

18. Sun, Y.; Wang, M.; Alejandro, L.; Mur, J.; Shen, Q.; Guo, S. Unravelling the Roles of Nitrogen Nutrition in Plant Disease Defences. Int. J. Mol. Sci. 2020, 21, 572. [CrossRef] [PubMed]

19. Menge, D.M.; Onyango, J.C.; Yamauchi, A.; Kano-Nakata, M.; Asanuma, S.; Thi, T.T.; Inukai, Y.; Kikuta, M.; Makihara, D. Effect of nitrogen application on the expression of drought-induced root plasticity of upland NERICA rice. Plant Prod. Sci. 2019, 22, 180-191. [CrossRef]

20. Sedri, M.H.; Amini, A.; Golchin, A. Evaluation of Nitrogen Effects on Yield and Drought Tolerance of Rainfed Wheat using Drought Stress Indices. J. Crop Sci. Biotechnol. 2019, 22, 235-242. [CrossRef]

21. Tran, T.T.; Kano-Nakata, M.; Takeda, M.; Menge, D.; Mitsuya, S.; Inukai, Y.; Yamauchi, A. Nitrogen application enhanced the expression of developmental plasticity of root systems triggered by mild drought stress in rice. Plant Soil 2014, 378, 139-152. [CrossRef]

22. Li, S.; Zhou, L.; Daniel, S.D.A.; Guochang, D.; Sun, M.; Wu, S.; Lin, S. Nitrogen supply enhances the physiological resistance of Chinese fir plantlets under polyethylene glycol (PEG)-induced drought stress. Sci. Rep. 2020, 10, 1-8. [CrossRef] [PubMed]

23. Dinh, T.H.; Watanabe, K.; Takaragawa, H.; Nakabaru, M. Photosynthetic response and nitrogen use efficiency of sugarcane under drought stress conditions with different nitrogen application levels. Plant Prod. Sci. 2017, 1008, 1-11. [CrossRef]

24. Haefele, S.M.; Kato, Y.; Singh, S. Field Crops Research Climate ready rice: Augmenting drought tolerance with best management practices. Crop. Res. 2016, 190, 60-69. [CrossRef]

25. Zhong, S.; Xu, Y.; Meng, B.; Loik, M.E.; Ma, J.Y.; Sun, W. Nitrogen addition increases the sensitivity of photosynthesis to drought and re-watering differentially in C3 versus C4 grass species. Front. Plant Sci. 2019, 10, 1-17. [CrossRef]

26. Evans, J.R. Photosynthesis and nitrogen relationships in leaves of C3 plants. Oecologia 1989, 78, 9-19. [CrossRef]

27. Abid, M.; Tian, Z.; Ata-ul-karim, S.T.; Cui, Y.; Liu, Y. Nitrogen Nutrition Improves the Potential of Wheat (Triticum aestivum L.) to Alleviate the Effects of Drought Stress during Vegetative Growth Periods. Front Plant Sci. 2016, 7, 1-14. [CrossRef] [PubMed]

28. Gao, J.; Luo, Q.; Sun, C.; Hu, H.; Wang, F.; Tian, Z.; Jiang, D.; Cao, W.; Dai, T. Low nitrogen priming enhances photo-synthesis adaptation to water-deficit stress in winter wheat (Triticum aestivum L.) seedlings. Front. Plant Sci. 2019, 10, 1-11. [CrossRef]

29. Heckathorn, S.A.; DeLucia, E.H.; Zielinski, R.E. The contribution of drought-related decreases in foliar nitrogen concentration to decreases in photosynthetic capacity during and after drought in prairie grasses. Physiol. Plant. 1997, 101, 173-182. [CrossRef]

30. Chen, D.; Wang, S.; Xiong, B.; Cao, B.; Deng, X. Carbon/nitrogen imbalance associated with drought-induced leaf senescence in sorghum bicolor. PLoS ONE 2015, 10, e0137026. [CrossRef]

31. Kong, L.; Xie, Y.; Hu, L.; Si, J.; Wang, Z. Excessive nitrogen application dampens antioxidant capacity and grain filling in wheat as revealed by metabolic and physiological analyses. Sci. Rep. 2017, 7, 1-14. [CrossRef]

32. Iqbal, A.; Dong, Q.; Wang, X.; Gui, H.; Zhang, H.; Zhang, X.; Song, M. High Nitrogen Enhances Drought Tolerance in Cotton through Antioxidant Enzymatic Activities, Nitrogen Metabolism and Osmotic Adjustment Asif. Plants 2020, 9, 178. [CrossRef] [PubMed]

33. Laxa, M.; Liebthal, M.; Telman, W.; Chibani, K.; Dietz, K.J. The role of the plant antioxidant system in drought tolerance. Antioxidants 2019, 8, 94. [CrossRef] [PubMed]

34. Chang, Z.; Liu, Y.; Dong, H.; Teng, K.; Han, L.; Zhang, X. Effects of cytokinin and nitrogen on drought tolerance of creeping bentgrass. PLoS ONE 2016, 11, e0154005. [CrossRef]

35. Hasanuzzaman, M.; Fujita, M. Exogenous sodium nitroprusside alleviates arsenic-induced oxidative stress in wheat (Triticum aestivum L.) seedlings by enhancing antioxidant defense and glyoxalase system. Ecotoxicology 2013, 22, 584-596. [CrossRef]

36. He, H.; Oo, T.L.; Huang, W.; He, L.; Gu, M. Nitric oxide acts as an antioxidant and inhibits programmed cell death induced by aluminum in the root tips of peanut (Arachis hypogaea L.). Sci. Rep. 2019, 9, 1-12. [CrossRef]

37. Guo, Z.; Ou, W.; Lu, S.; Zhong, Q. Differential responses of antioxidative system to chilling and drought in four rice cultivars differing in sensitivity. Plant Physiol. Biochem. 2006, 44, 828-836. [CrossRef]

38. Shehab, G.G.; Ahmed, O.K.; El-beltagi, H.S. Effects of Various Chemical Agents for Alleviation of Drought Stress in Rice Plants (Oryza sativa L.). Not. Bot. Horti Agrobot. Cluj-Napoca 2010, 38, 139-148.

39. Fukudome, M.; Watanabe, E.; Osuki, K.I.; Uchi, N.; Uchiumi, T. Ectopic or over-expression of class 1 phytoglobin genes confers flooding tolerance to the root nodules of lotus japonicus by scavenging nitric oxide. Antioxidants 2019, 8, 206. [CrossRef]

40. Del Río, L.A. ROS and RNS in plant physiology: An overview. J. Exp. Bot. 2015, 66, 2827-2837. [CrossRef]

41. Radi, R. Oxygen radicals, nitric oxide, and peroxynitrite: Redox pathways in molecular medicine. Proc. Natl. Acad. Sci. USA 2018, 115, 5839-5848. [CrossRef] 
42. Chamizo-ampudia, A.; Sanz-luque, E.; Llamas, A.; Galvan, A.; Fernandez, E. Nitrate Reductase Regulates Plant Nitric Oxide Homeostasis. Trends Plant Sci. 2017, 22, 163-174. [CrossRef] [PubMed]

43. Rubbo, H.; Radi, R.; Anselmi, D.K.; Marion, B.; Stephen, B.; John, E.; Jason, P. Nitric oxide reaction with lipid peroxyl radicals spares alpha-tocopherol during lipid peroxidation. J. Biol. Chem. 2000, 275, 10812-10818. [CrossRef]

44. Jain, P.; Singh, N.; Kaur, H. Mechanisms of nitric oxide crosstalk with reactive oxygen species scavenging enzymes during abiotic stress tolerance in plants. Free Radic Res. 2015, 50, 291-303. [CrossRef]

45. Hasanuzzaman, M.; Hossain, M.A.; Fujita, M. Nitric oxide modulates antioxidant defense and the methylglyoxal detoxi-fication system and reduces salinity-induced damage of wheat seedlings. Plant Biotechnol. Rep. 2011, 5, 353-365. [CrossRef]

46. Umnajkitikorn, K.; Faiyue, B.; Saengnil, K. Enhancing Antioxidant Properties of Germinated Thai rice (Oryza sativa L.) cv. Kum Doi Saket with Salinity. Rice Res. Open Access 2013, 4, 1-8. [CrossRef]

47. Beauchamp, C.; Fridovich, I. Superoxide dismutase: Improved assays and an assay applicable to acrylamide gels. Anal. Biochem. 1971, 44, 276-287. [CrossRef]

48. Vaidyanathan, H.; Sivakumar, P.; Chakrabarty, R.; Thomas, G. Scavenging of reactive oxygen species in NaCl-stressed rice (Oryza sativa L.)—Differential response in salt-tolerant and sensitive varieties. Plant Sci. 2003, 165, 1411-1418. [CrossRef]

49. Sunohara, Y.; Matsumoto, H. Oxidative injury induced by the herbicide quinclorac on Echinochloa oryzicola Vasing and the involvement of antioxidative ability in its highly selective action in grass species. Plant Sci. 2004, 167, 597-606. [CrossRef]

50. Bradford, M.M. A rapid and sensitive method for the quantitation of microgram quantities of protein utilizing the prin-ciple of protein-dye binding. Anal. Biochem. 1976, 72, 248-254. [CrossRef]

51. Fukudome, M.; Calvo-Begueria, L.; Kado, T.; Osuki, K.I.; Rubio, M.C.; Murakami, E.I.; Nagata, M.; Kucho, K.I.; Sandal, N.; Stougaard, J.; et al. Hemoglobin LjGlb1-1 is involved in nodulation and regulates the level of nitric oxide in the Lotus japonicusMesorhizobium loti symbiosis. J. Exp. Bot. 2016, 67, 5275-5283. [CrossRef] [PubMed]

52. Signorelli, S.; Corpas, F.J.; Borsani, O.; Barroso, J.B.; Monza, J. Water stress induces a differential and spatially distributed nitro-oxidative stress response in roots and leaves of Lotus japonicus. Plant Sci. 2013, 201-202, 137-146. [CrossRef] [PubMed]

53. Available online: https://imagej.nih.gov/ij/docs/examples/stained-sections/index.html (accessed on 16 February 2021).

54. Brumbarova, T.; Le, C.T.T.; Bauer, P. Hydrogen Peroxide Measurement in Arabidopsis Root Tissue Using Amplex Red. Bio-protocol 2016, 6, 1-11. [CrossRef] 